\title{
Students' Perceptions Of Ethnicity and Learning: A case study of the United States International University (USIU)
}

\author{
Katsuji Nakamura
}

\section{Abstract}

Kenya is an ethnically diverse country comprising over forty ethnic groups. While the diversity should make up the richness of culture and ways of life, the 'tribe' mentality is the root cause of many problems that Sub-Sahara African nations face. In Africa, different ethnic groups compete for national resource such as "land, political power, natural resources, social and economic power" (Osore 2008), and "tribalism still infuses all aspects of society" (Wax 2005). Sadly, higher education does not seem to be an exception.

That could be the reason why in the past, the Kenyan Government used to exercise a lot of control over the public universities in terms of contents of curriculum, hiring and firing of staff and lecturers, approving conference and seminars, among many others, in order to meet its own political ends, thus curtailing academic freedom (Mwiria 2001). After the introduction of multipartism in 1992, the situation began changing with the State and other political formations now competing to influence the educational sector.

For instance, some months before the general election in December 2007, many of the student bodies of the public universities' were reportedly re-aligned to one of three major political forces of the time, which were aligned to some ethnic groups.

"Tribalism and ethnicity have almost become the second name for the student body," and "the tribal politics being played out between the ODM and the $\mathrm{PNU}^{1}$ groupings have been extended wholesale to the student community"2. During the last General Election, the two leading political parties of the time approached the Students Affairs Council, the students' Affairs body at United States International University (USIU), a private university, but the student officials declined to be associated with any of the political parties, as it was against the policy of the university ${ }^{3}$. Consequently, there was no election campaign that took place on the USIU campus.

This paper attempts to investigate whether or not ethnicity is a determinant of student learning at university in a country like Kenya that is rocked by ethnic violence.

\footnotetext{
${ }^{1}$ The two competing party coalitions: ODM (Orange Democratic Movement) and PNU (party of National Unity)

${ }^{2}$ Daily Standard 18 October 2007

${ }^{3}$ USIU Gazette of Fall 2008.
} 


\section{Introduction}

The episode above does not guarantee that USIU is free from any negative ethnicity since it is still part of Kenyan society in terms of both population and culture. Therefore, we cannot even rule out the possibility of ethno-nationalism taking some form in a big way in the future, if left unchecked. Or there may be already some kinds of ethnic discrimination or bias that affect the learning on the campus, yet that is not known so much. Is there, for instance, any favoritism or discrimination against students from certain ethnic groups by some lecturers? Even if there isn't, are there some students who have some anxiety or fear of being discriminated against by lecturers from different ethnic backgrounds, which may psychologically impede their learning to some extent? Is student interaction with administration free from ethnic bias? We contend that any negative ethnicity on the campus would seriously jeopardize learning at the university.

\section{Ethnicity and the Academy: a review}

Higher education has an impact on the future of the society and therefore shapes the course of the world. Indeed, Daisaku Ikeda, founder of Soka University in Tokyo and California, says "Universities are places to raise people with new aspiration and leadership that respond to the ever changing society. Universities, therefore, play the central role in any civilization. The future of a society depends on what types of graduates universities produce" (Ikeda 1990). If we are to envision the future society where people take pride in their ethnic origin, yet are able to transcend the differences and to appreciate the strengths of other people, then a tolerant, allembracing culture must become a way of life at the higher education. It is this argument that underlies the present study.

In order to take a step towards the harmonious multi-ethnic university community, we need to first establish the current position of the state in terms of how the ethnic diversity affects the learning. This preliminary survey is therefore meant to be the first step, exploring the current situation of the students' perceptions on the impact of ethnicity on learning at a higher educational institution in Kenya, taking a private university, United States International University, as a case.

The issue of the ethnicity can be, however, very sensitive in Kenya. Indangasi (2008) argues that many Kenyans have obsessing interest in the tribal origin of others, although of course the degree of the interest may differ from one person to the other. Kenya is indeed a place, "where, as in most of Africa, it often overrides any sense of nationalism" and political parties "form along tribal, not ideological, lines, and opportunities often stem from blood ties" (Wax, Ibid). Against this background, any attempt to delve into the issue of ethnicity can be treated with suspicion.

Probably this sensitivity of the issue explains why there seems to be no substantial research and literature in the area of ethnicity. There are some researches on the differences of performance of learning among different ethnic groups / races (For example, Greenfield, Teresa Arámbula 1996, Keitel, C. (Ed.) 2000, Brooks, Ann K, 
Tamara Clunis 2007). But they are on general difference of ethnic groups / races in achievements, performance or learning habits, and not on how the ethnic enmity affects the learning. In that regard, C. J. Adigwe's “Ethnicity, Test Anxiety and Science Achievement in Nigerian Students" (1997) is closest to the theme of the present study in that it deals with African context and it also focuses on learners' psychological state in the learning process according to ethnicity.

There are also other researches on how the factors such as different sociocultural background among the different ethnicity in U.S. affect the learning achievements (Okagaki and Frensch 1998, Portes 1999, etc.) and on how the mainstream culture in U.S. neglects the culture of minority who consequently achieve much less in the public schools (Ogbu 1992). But none of these studies, however, deal with how the ethnic animosities can impact learning.

Yet, considering what happened for several months after the 2007 General Election in Kenya that plunged the country into total chaos and violence, the magnitude of the matter cannot be overemphasized. There is need to change the nature of relationships among the ethnic groups from the acrimonious to the constructive for the sake of peace and development of the country.

Doh Joon Chien for instance argues in his paper, "Ethnicity and Development: The Baba-Ali Approach" (1982), that the economic policy to ensure constructive interaction among different ethnicity in Malaysia led her to the successful development. It is the wish of the author, therefore, that this study would open the new area of research which has been thus far perceived to be a taboo area, and it will eventually contribute to the creation of the constructive interaction of diverse ethnicity, which will lead to the development of the nation.

\section{Methodology}

The goal of the present study is to explore the perception of the students at United States International University on the extent to which 'tribalism' affects their learning in the campus. It utilizes the survey research method with mainly quantitative questions with inclusion of the component of qualitative questions.

The following are the basic research questions:

- Do the students at USIU think that there is tribalism or ethnic bias at USIU?

- Is the teaching staff at USIU free from any kind of ethnic bias or favoritism?

- Do the students take the ethnicity of the lecturer into consideration when registering for courses, or do they feel comfortable with lecturers from any ethnic background?

- $\quad$ Did the post-election violence in January 2008 and the polarization of the country along ethnic lines affect the learning of the students? If so, how?

- Do the students think that learning at USIU helps them go above the ethnic prejudices? 
In order to elicit the answers to the above questions, a questionnaire was prepared. There are six questions in the questionnaire, with scores on a five scale point, ranging from strongly agree to strongly disagree, and each of these quantitative questions is followed by a qualitative question that is meant to uncover the reasons, thoughts or any specific experiences the students have / had for their answers on a five-point scale. These include questions such as "Any specific reasons / experiences?"

These are the qualitative questions in the questionnaire which the respondents marked one on a five scale:

1) The learning at USIU is free from tribalism / ethnic bias.

2) Teaching staff at USIU is free from tribalism / ethnic bias in their works.

3) I am sometimes not comfortable with taking courses with some lecturers because of his / her ethnicity.

4) When registering courses, I care about the ethnic background of the lecturers.

5) The post-election violence affected my learning.

6) The learning environment of USIU helps students transcend ethnic differences.

I gave out the questionnaires to the students of the two different Japanese language courses that I taught in April, 2008. All of 56 students present in the classes on the day completed the questionnaires onsite. Japanese at USIU is part of general education and elective courses, and all the students in the university are to take one foreign language out of six different languages.

The students of all the years and the degree courses offered at USIU are represented in the samples of the questionnaires. However, some major ethnic groups in Kenya were underrepresented in comparison with the ethnic demography in the country, and in order to get more reliable and balanced data, 14 more samples were collected from the students of these ethnic origins outside the classrooms. Therefore, the total number of the subjects became 70 . The statistics of the bio data of the subjects are as follows:

The number of the students for:

a) Each degree course:

International Business Administration 40

Business Administration 4

International Relation $\quad 5$

Psychology 3

Journalism 7

Information System and Technology 8

Hotel and Restaurant Management 2 
b) Year of study: Freshman 4, Sophomore 8, Junior 26, Senior 31, Unknown 1

c) Sex: Male 33, Female 37

d) Age: (16-20 year old): 1, (21-25): 53, (26-30): 12, (30-40):2, (40 and above): 1, (unknown): 1

e) Ethinic (or Racial) Background: Kikuyu 25, Luyha 8, Luo 9, Kalenjin 7, Kenyan of Asian / Arab origin 6, Kamba 2, Kisii 2, Turkana 1, Rendile 1, Meru 1, foreiners (Ugandan, Ethiopian, Tanzanian) 3, unknown 5.

The qualitative data is analyzed at two levels: Analysis of general trend, and comparison between male and female respondents, which is to see if there is any difference of perception / experiences between sexes. In citing the comments of the respondents, some words are added in parenthesis, when necessary, in order to clarify the context of the sentences.

\section{Findings and Discussion}

1) The learning at USIU is free from tribalism / ethnic bias.

\begin{tabular}{|llllll|}
\hline & Strongly Agree Agree & Neither & Disagree & Strongly Disagree \\
\hline General & 28.57 & 32.86 & 25.71 & 12.86 & 0 \\
\hline & & & & & \\
\hline Male & 18.18 & 39.39 & 24.24 & 18.18 & 0 \\
\hline Female & 37.84 & 27.03 & 27.03 & 8.110 & \\
\hline
\end{tabular}

For both questions, majority (61.4\% [strongly agree or agree]) of the students said that USIU is free from tribalism and ethnic bias. Although the population who disagreed with the statement is small $(12.86 \%)$, it is noteworthy that about a quarter of the subjects had reserved opinion (neither) on the issue. The female students (65.14\% [strongly agree / agree]) seem to be more positive about it than male counter part $(57.57 \%)$. It is also interesting that the percentage of the female who disagreed $(8.11 \%)$ is less than half the male $(18.18 \%)$.

For the reasons they cited for their agreement are such as "The people of different backgrounds study together (at USIU)," "It (USIU) advocates for non-discrimination of whatever kind," "The people intermingle without worrying about ethnic background," and "the fact that people are used to speaking English everywhere anytime does not give room to distinguish tribes." The factors such as multicultural / international outlook of the population, common usage of English as their means of communication, and the university policy of non-discrimination seems to be reaping some dividends here.

But there were also negative comments. A student alleged, "There is tribalism especially on the security desk and the lecturers' side." There is also a student who 
practices of tribalism: "When you speak, people seem to identify your accent so as to categorize the ethnicity and see whether to discriminate or not," "Some people do communicate freely in their native languages, though it's not so strong," and "Some students speak mother tongue in groups." Thus, while English is dominant language in the campus that seems to play a part in bringing people from different backgrounds together, some students with same ethnic background seem to prefer to communicate in their indigenous language for some reasons, probably reasons such as communicating with more ease, establishing group identity, or keeping secrecy of the content of conversation from others.

2) Teaching staff at USIU are free from tribalism / ethnic bias in their work.

\begin{tabular}{|llllll|}
\hline & Strongly Agree & Agree & Neither & Disagree & Strongly Disagree \\
\hline General & 20 & 40 & 24.29 & 15.71 & 0 \\
\hline & & & & & 0 \\
\hline Male & 24.24 & 39.39 & 27.27 & 9.09 & 0 \\
\hline Female & 16.22 & 40.54 & 21.62 & 21.62 & 0 \\
\hline
\end{tabular}

$60 \%$ of the respondents, just like the first question, say that the teaching staffs are professional and unbiased in terms of the ethnic bias. Only $15.71 \%$ disagreed and no one strongly disagreed. For this statement, the male students supported the statement slightly more than the females.

Reasons given for their agreement are such as, "I haven't really experienced any 'major' ethnic bias from my learning," or "Staffs generally don't display any biases they may have."

However, there are a couple of reserved comments such as "No way of knowing," and "Tribalism is deep rooted in Kenya. Although we are trying to fight it, I cannot defend anyone." Besides, there are also a few disapproving examples cited such as, "A female lecturer once made very ethnic statements in class," "(A male lecturer gave illustrations from his community only," and "During the skirmishes (after the disputed election in 2007) you could tell which side they relied on, especially on their tribesmen."

There were also others who quoted specific cases of favoritism: "Some lecturers are not biased but others are; for example, I know of a lecturer who favors the Asians in the class," "Some lecturers favor white people," "Some staffs favor the foreigners," and "Some lecturers favor their tribes." There were also three students who voiced their doubts about favoritism in "grade awarding." We do not know whether these are the facts, suspicions or interpretations of the teaching staffs' conducts, but it is very advisable for the teachings staffs to remain unbiased and avoid any words or behaviors that may give wrong impressions to the students. 
Thompson (1981) argues that teachers' attitude and classroom management style contribute to learners' character building that would have impact on democracy; that is to say, whether a person grows to be critical thinker and active participant in democracy, or docile and passive member of society. The lecturers' attitude towards ethnicity likewise can also have impact on the students' attitude and thought on the issue. Therefore, we, the teaching staffs at higher education, should be the first to fight the negative ethnic orientation within and to try hard to stay above it, as Mahatma Gandhi says, "Be the change you want to see in the world."

3) I am sometimes not comfortable with taking courses with some lecturers because of his / her ethnicity.

\begin{tabular}{|lllllc|}
\hline & Strongly Agree & Agree & Neither & Disagree & Strongly Disagree \\
\hline General & 0 & 11.43 & 11.43 & 42.86 & 34.29 \\
\hline & & & & & \\
\hline Male & 0 & 21.21 & 15.15 & 48.48 & 15.15 \\
\hline Female & 0 & 2.70 & 8.11 & 37.84 & 51.35 \\
\hline
\end{tabular}

For this section, the majority of the students $(77.15 \%)$ disagreed with this statement. In particular, $89.19 \%$ of the female students differed with it, with only $2.7 \%$ expressing the discomfort with the lecturers' ethnicity. The male counterpart is however comparably lower in their disagreement $(63.63 \%)$ than the female, while $21.21 \%$ feel uncomfortable with some lecturers due to their ethnic background, almost 8 times more than the female's rate.

Reasons given for their disagreement were, for instance, "I am not bothered by lecturer's ethnicity but whether the way of teaching is interesting," "Lecturers don't care about someone's background, at least the ones I have dealt with," "It doesn't bother to me as I appreciate all cultures," "I have never experienced it or heard of anyone who has gone through it," and "I have never had any indication that lecturers are ethnically biased." It indicated that the majority of the students do not have much fear or anxiety about the lecturers' ethnic backgrounds, and that they are comfortable with the staffs regardless of their ethnicity. 
Yet, there were few that held reservation or suspicions, thus, "It's full of different ethnic cultures so one can't evade," "Personally I have not experienced it, but my friends have," "Some may be tribalistic," and "I fear of ethnic bias."

There are such sentiments from few students notwithstanding, for this section it can be safely said that the lecturers' ethnicity is not a factor that can make them uneasy to register courses, and female students are notably freer from any anxiety about it than the male. Very similar is the trend of the next question.

4) When registering courses, I care about the ethnic background of the lecturers.

\begin{tabular}{|lllllc|}
\hline & Strongly Agree & Agree & Neither & Disagree & Strongly Disagree \\
\hline General & 1.43 & 4.29 & 10 & 37.14 & 47.14 \\
\hline & & & & & \\
\hline Male & 3.03 & 6.06 & 18.18 & 45.45 & 27.27 \\
\hline Female & 0 & 2.70 & 2.70 & 29.73 & 64.86 \\
\hline
\end{tabular}

Most of the students ( $84.28 \%$ ) said they do not take into consideration the ethnicity of the lecturers, and only $5.72 \%$ said they do care about the ethnicity of the lecturers when registering courses. The female is still more positive about their disagreement than the previous question, with startling rate of $94.59 \%$ disagreeing with the remark. Though the percentage of the disagreement is higher than that of the foregoing question, it is conspicuous that the male students are less liberal about the ethnicity than the female, with $72.72 \%$ differing with the statement.

Written in the questionnaires are comments such as "I only care how the lecturers teaches and how I can get my A (grade) at the end," "That has never occurred to me," "it doesn't matter to me," "I am here only to learn; they are here only to teach," and "Ethnic background does not determine the level of teaching." Overwhelming majority, therefore, seems to take courses regardless of the ethnicity of the lecturers, and what determines the choice is probably factors such as the pedagogical skills, personality and grading patterns rather than the ethnicity of the teachers.

5) The post-election violence affected my learning.

\begin{tabular}{|lllllc|}
\hline & Strongly Agree & Agree & Neither & Disagree & Strongly Disagree \\
\hline General & 24.29 & 25.71 & 17.14 & 24.29 & 8.57 \\
\hline & & & & & \\
\hline Male & 18.18 & 33.33 & 15.15 & 21.21 & 12.12 \\
\hline Female & 29.73 & 18.92 & 18.92 & 27.03 & 5.41 \\
\hline
\end{tabular}


The controversial results of the presidential election in Kenya that took place towards the end of 2007 triggered the several months of chaos and violence in many parts of the country. Indeed, the country was torn apart both physically and spiritually. It was a time when "the political tensions and ethnic suspicions became part of our national psyche," and "even the most gifted among us are experiencing difficulties trying to rise above it (Indangasi Ibid)." The author also personally witnessed that most of Kenyan people became hyper-conscious of ethnicity of self and others, and began regrouping along the ethnic lines.

The mayhem did affect the education industry as well. Ministry of Education was forced to delay the opening day of the public schools, and national universities did the same. Even after the delay of the reopening, public universities, for instance, were reported to be "grappling with issues of safety, low attendance, accommodation, disruption of academic programmes and staff and student transfer requests." At Moi University " 13 houses were burnt," and according to the Universities Academic Staff Union, "more than 400 lecturers were adversely affected and might not resume teaching in public universities" (Daily Standard, 26 February 2008).

USIU was not an exception either. The opening day of the spring semester was delayed by a week, and even after the delayed opening, about half the students were yet to report to the campus in the first week of the term, mainly due to the lack of the transport from the western part of Kenya to Nairobi.

Against this background, the current section of the questions was to find out the damage the turbulent period incurred on the learning at USIU.

Half of the sample, i.e. (50\%) agreed with the remark while $(32.86 \%)$ disagreed. For this question, there is not so much difference between the male and female, and the distribution of the percentage for both sexes is almost same, which indicates that the country's chaos affected them regardless of gender. It is also evident that quite a number of students were affected by the post-election violence, directly or indirectly.

There were quite a number of students who mentioned they had to miss classes due to insecurity or unavailability of unreliable transport. For example, "Poor transportation access from my home and insecurity; thus I could not attend some classes," "It was difficult to concentrate (on study) because sometimes we had to miss class," "I had to miss some of the classes," "I came to school late and had missed a few of my classes," "The class started late and my mind thought a lot about security," "Insecurity, inconsistency in transport facilities, lecturers attendance," etc.

They are also not few who said they reported late to the university due to lack of transport from their rural home: "The fare was hiked and there were no vehicles from Turkana, so I couldn't not come to school on time," and "I came to school two weeks late."

There were also some who come from badly affected areas: "I came late from Rift Valley, as members from our ethnicity were being targeted to move out" 
(the student is from Eldoret), "My district was affected" (the student come from Murang'a), and "The fee became a problem as the businesses were highly affected" (student from Nyeri), "I was forced to drop the two night class I had because my life was threatened" (a Luo female student), "It affected me, because I was in Western province during the violence, and seeing people dying in cold blood was really horrifying."

Some of the foreign students were also not spared either. There is a Tanzanian student who said "I came late to school because my parents were worried and still are, so it affected me, though it is not a big deal to me because it is not affecting me personally."

But to some, it was business as usual: "Learning went on as usual," "I was able to commute to and from school," "I am a Ugandan, so it really didn't affect me that much," and "Except for fear that school would close, it did not affect learning." It seems that the level of the impact of the post-election violence on their learning differed from a student to the other to a great deal, depending on factors such as the areas the students come from or their individual situations. Nevertheless, despite all the odds some of them faced during the period, it seems that the learning of the university as a whole went on without serious setbacks and most of the affected students also somehow managed to weather the difficult time.

6) The learning environment at USIU helps students transcend the ethnic differences.

\begin{tabular}{|llcclcl|}
\hline & Strongly Agree & Agree & Neither & Disagree Strongly Disagree & Unknown \\
\hline General & 44.29 & 40 & 11.43 & 1.43 & 1.43 & 1.43 \\
& & & & & 3.03 & 0 \\
\hline Male & 42.42 & 39.39 & 15.15 & 0 & 0 & 2.70 \\
\hline Female & 45.95 & 40.54 & 8.11 & 2.70 & \\
\hline
\end{tabular}

Vast majority ( $84.29 \%$ ) in total agreed that the learning environment of the university helps put them above the ethno-centrism, and only $2.86 \%$ disagreed. For this again, the female is slightly more assertive $(86.49 \%)$ than the male $(81.81 \%)$.

Some of the reasons given are such as "Interaction with many ethnic groups allows one to create a new self image that is not ethnic in nature"," "It accommodates everyone from different walks of life," "We don't focus on ethnic differences but learn how to embrace the diverse culture in the initiation (he means probably the orientation)," "Learning of other culture," "Diversity makes it easier," "Because the international students don't ask about your tribe," "There is a mix of ethnic backgrounds, which helps one expand their views," "Multicultural environment," "Very diverse and we have common goals, for instance, to learn and grow," "I was tribal when I came here but now am far from that," "People encouraged to talk in 
English and intermarry," "Opportunities mostly are shared equally," etc. Multicultural environment, the emphasis on the multicultural understanding in the university's mission and program, and internationality of the population, both students and faculty alike, seem to be some of the main elements that contribute to the consent of the majority to the statement.

The high percentage of this agreement clearly shows that despite the presence of tribalism in all the spheres of the society in Kenya, the students think that the education and learning environment at USIU helps them metamorphose into better persons who are free from ethnicism. There was only one dissenting view which said, "I don't really see it around because some students like Indians are always alone."

According to some educationists, social problems we have in Kenya such as indiscipline, immorality and all forms of corruption are due to the failure of the school curriculum. (Benaars, Otieno, Wamahiu 1990). Yet, at least USIU's education seems to offer a catalyst for the betterment of the society. With its strong multicultural outlook, orientation, curriculum and policy, the university can be a regional leader in the cause to eradicate negative ethnicity.

\section{Conclusion and Suggestion for the further research}

Generally speaking, it was found that majority of the students at United States International University do not see significant impact of tribalism on learning in the campus. Most of them feel that the learning and teaching staffs at the university are free from the ethnic bias, and they say they do not mind about the ethnicity of the lecturers when they register the courses.

The vast majority also believe that the learning at USIU help them develop the multicultural understanding and transcend the ethnic differences. The university's overall policy, curriculum, and learning environment, both human and physical, may have attributed to the positive perception found in the survey. It is also worth mentioning that the female students in general seem to be more positive about their opinions on non-tribalistic nature of the learning on the campus than the male counterparts.

It should also be noted however that there are also a few students who witnessed or experienced a few cases of discrimination / favoritism in terms of ethnicity in classrooms and on campus, which probably calls for more comprehensive research to establish whether they are really isolated cases or not.

It also indicated that the post-election violence did affect the learning of significant number of students, many of whom reporting to the university late or having troubles to commute to and from the campus. 
The number of respondents is quite few in comparison with the total number of the students in the campus, and the present study is therefore by no means conclusive, but exploratory.

Furthermore, there is also need to investigate the same in other private and public universities to find out the general trend in the country, because any findings of investigation on the students' perception at USIU has limitation due to the university's socio-economical, cultural and philosophical context, and they cannot be generalized to represent the situation in the higher education in Kenya. A better view of the situation can be captured, therefore, only after the wider research is conducted. Furthermore, more comprehensive, nation-wide research can be also conducted across the education sector to probe the same of different age groups. All these extensive survey may help the policy makers and administrators of schools and colleges to formulate new policies to tackle the country's malady and to steer it to the right direction. What could be the right direction?

The right direction should be towards changing the people's ethnically-oriented mind-set that is replete with hatred and prejudice against other communities. It should be towards creating an institutional culture within the education sector that shuns negative ethnicity. However, culture dies hard. It is the contention of the present study, therefore, that there is need to embark on proactive campaigns in the education sector to address the root cause of the malady that the continent suffers from since decades. 


\section{Acknowledgment}

I would like to express great appreciation to my assistant, Kenneth Kamau, for tallying and tabulating the data of the questionnaires. His assistance made the work a lot easier.

\section{References}

Adigwe, J. C. (1997), “Ethnicity, Test Anxiety And Science Achievement In Nigerian Students," International Journal of Science Education, Volume 19, Issue 7 August 1997, $773-780$

Benaars, Gerald, James Otieno and Sheila Wamahiu (Eds.) (1990). Social Foundation and Ethics: Developing a New Area of Learning. Professors World Peace Adcademy of Kenya. 93.

Brooks, Ann K, Tamara Clunis (2007), “Where to Now? Race and Ethnicity In Workplace Learning And Development Research: 1980-2005," Human Resource Development Quarterly Volume 18, Issue 2, 2007, 229-251

Chien, Doh Joon (1982), "Ethnicity and Development: The Baba-Ali Approach," a paper presented at the National Conference of the American Society for Public Administration in Honolulu, Hawaii.

Education Team, "Varsities Fight Transfers As They Rework Their Calendar," Daily Standard, 26 February 2008

Greenfield, Teresa Arámbula (1996), “Gender, Ethnicity, Science Achievement, and Attitudes," Journal of Research in Science Teaching, Volume 33, Issue 8, 1996, 901-933

Ikeda, Daisaku (1990), From Today Onward: For Future Division vol. 1, Tokyo: Seikyo Press. 124

Indangasi, Henry (2008), "Preface," in Henry Indangasi \& Masumi O. Hashimoto (Eds.), Daisaku Ikeda and Voices for Peace from Africa, Nairobi: Kenya Literature Bureau. $x-x i$

Keitel, C. (Ed.) (1998), Social Justice and Mathematics Education: Gender, Class, Ethnicity and the Politics of Schooling, Berlin: Freie Universität Berlin and International Organization of Women and Mathematics 
Mahatma Gandhi, from http://thinkexist.com

Murigi, Peter, Stephen Makabila and Steve Mkawale, "Campaigns Target Campus Students," Daily Standard, 18 October 2007

Mwiria, Kilemi (2001), “Democratizing Kenya's Public Universities” in Otiende, James E, Njoroge George K (Eds.), Education Gender and Democracy in Kenya, Friends - Book Foundatiuon: Nairobi. 138 - 141

Okagaki, Lynn, Peter A. Frensch (1998), “Parenting and Children's School Achievement: A Multiethnic Perspective," American Educational Research Journal, Vol. 35, No. 1, 123-144

Ogbu, John U. (1992), "Understanding Cultural Diversity and Learning,"Educational Researcher, Vol. 21, No. 8, 5-14

Osore, Miriam Kenyani (2008), "Jesus Christ and the Philosophy of Peaceful Coexistence," in Henry Indangasi \& Masumi O. Hashimoto (Eds.), Daisaku Ikeda and Voices for Peace from Africa, Nairobi: Kenya Literature Bureau. 110

Portes, Pedro R. (1999), "Social and Psychological Factors in the Academic Achievement of Children of Immigrants: A Cultural History Puzzle," American Educational Research Journal, Vol. 36, No. 3, 489-507

Thompson, A.R. (1981), Education and Development in Africa, London: Macmillan. 40

Wax, Emily, "Growing Beyond the Pull of the Tribe in Kenya: Nairobi Teenagers Find New Unity in Contemporary Culture, Even as Old Ties Persist," Washington Post Foreign Service, Sunday, September 18, 2005 